\title{
Promoting electric vehicle uptake, a job for the NHS?
}

\begin{abstract}
A Royal College of Physicians' report in 2016 found that air pollution in the UK causes 40,000 excess deaths each year. This problem is particularly bad at hospitals and health centres. A recent British Lung Foundation report found that one in four hospitals in England are located in areas that have dangerously high levels of particulate matter air pollution. ${ }^{2}$ To address this issue, the UK government has a long-standing ambition to have almost all cars produce zero emissions by 2050 and the House of Commons recently recommended a more ambitious target of 2032. ${ }^{3}$ The NHS has set out specific goals to reduce air pollution in its The NHS Long Term Plan, aiming to reduce emissions from its transport fleet and business mileage by $20 \%$ by $2023 .{ }^{4}$ To meet this target, the number of electric vehicles (EVs) must increase significantly. EVs do not emit exhaust gases and particulates at the roadside and so they may be important in improving air quality. However more widespread adoption of EVs is limited by inadequate charging infrastructure. As this is an important public health matter, one might expect the NHS to have taken the lead in providing charging points to support the uptake of EVs. This is particularly relevant as the NHS has 442,924 parking spaces across England alone, and is one of the UK's largest providers of parking. Analysis of the estates returns information collection data for England 2017-18 demonstrates that the NHS in England only provides 1,305 EV charging points, accounting for only $0.29 \%$ of all parking spaces. Eighty-three per cent of NHS sites have no charging points at all. These figures are even worse than they initially appear, as nearly half of those charging points (580) are in fact at a single site - the South Western Ambulance Service NHS Foundation Trust. If we exclude this location, then nationally $99.8 \%$ of NHS parking spaces are not equipped to charge EVs. ${ }^{5}$ It is estimated that NHS-related traffic accounts for $3.5-5 \%$ of road traffic in England. ${ }^{4}$ Charging an EV to $80 \%$ takes at least half an hour. As so many journeys per day already involve visiting NHS sites and many NHS sites have a shop or food/drink outlet, NHS sites may be ideal places to locate EV charging points. Significant changes are required nationally to support the uptake of EVs. We argue that the NHS has a responsibility to lead the way on
\end{abstract}

encouraging this healthier alternative to conventionally fuelled cars. With a national footprint, increased provision of charging points at NHS car parks could rapidly boost the national charging network and facilitate the adoption of EVs. This would contribute to the wider goals of zero emission transport and improved public health.

THOMAS WEATHERBY Foundation doctor, Royal Papworth Hospital, Cambridge, UK

JOHN SOMNER

Consultant paediatric ophthalmologist, Addenbrooke's Hospital, Cambridge, UK

\section{References}

1 Royal College of Physicians. Every breath we take: the lifelong impact of air pollution. Report of a working party. London: RCP, 2016. www.rcplondon.ac.uk/projects/outputs/every-breath-we-takelifelong-impact-air-pollution.

2 British Lung Foundation. Toxic air at the door of the NHS. BLF, 2016. www.blf.org.uk/take-action/campaign/nhs-toxic-air-report.

3 House of Commons Business, Energy and Industrial Strategy Committee. Electric vehicles: driving the transition. Fourteenth report of session 2017-19. London: House of Commons, 2019. https://publications.parliament.uk/pa/cm201719/cmselect/ cmbeis/383/383.pdf.

4 NHS England. The NHS Long Term Plan. NHS, 2019. www.longtermplan.nhs.uk/wp-content/uploads/2019/01/nhs-long-term-planjune-2019.pdf.

5 NHS Digital. Estates returns information collection, England, 201718. NHS, 2018. https://digital.nhs.uk/data-and-information/ publications/statistical/estates-returns-information-collection/ summary-page-and-dataset-for-eric-2017-18.

Address for correspondence: Dr Thomas Weatherby, Churchill College, Storey's Way, Cambridge CB3 ODS, UK.

Email: tw418@cam.ac.uk 